\title{
Advancing Geriatrics Education Through a Faculty Development Program for Geriatrics-Oriented Clinician Educators
}

\author{
Sandro O. Pinheiro, PhD, MA, MRE, ${ }^{* \dagger}$ Heidi K. White, MD, MHS, MEd, CMD ${ }^{* \dagger}$ \\ Gwendolen T. Bubr, MD, MHS, MEd, CMD, *广 Katja Elbert-Avila, MD, MHS, *t* \\ Harvey Jay Cohen, MD, ${ }^{* \dagger}$ and Mitchell T. Heflin, MD, MHS*广t
}

Geriatrician and nongeriatrician faculty need instruction as teachers to provide quality training for a broader community of physicians who can care for the expanding population of older adults. Educators at Duke University designed a program to equip geriatrician and nongeriatrician faculty to develop quality educational programs and teach medical learners about geriatrics. Eighty-three faculty representing 52 institutions from across the United States participated in mini-fellowship programs (2005-09) consisting of workshops and 1-year follow-up mentoring by Duke faculty. Participants attended 1-week on-campus sessions on curriculum development and teaching skills and designed and implemented a curriculum in their home institution. Participant specialties included general medicine (nearly 50\%), family medicine, surgery, psychiatry, rehabilitation medicine, and emergency medicine. Pre- and postprogram self-efficacy surveys, program evaluation surveys, and 6- and 12-month progress reports on scholars' educational projects were used to assess the effect of the Duke mini-fellowship programs on participants' educational practices. Forty-four scholars $(56 \%)$ completed the end-of-year self-efficacy survey and end-of-program evaluation. Self-efficacy results indicated significant gains $(P<.001)$ in 12 items assessed at 1 week and 1 year. Scholars reported the largest average gains at 1 year in applying adult learning principles in the design of educational programs (1.72), writing measurable learning objectives (1.51), and identifying optimal instructional methods to deliver learning objectives (1.50). Participants described improved knowledge and skills in designing curricula, implemented new and revised geriatrics curricula, and

From the "Division of Geriatrics, Department of Medicine, School of Medicine; ${ }^{\dagger}$ Center for the Study of Aging and Human Development, Duke University; and 'Geriatrics Research, Education and Clinical Center, Durham Veterans Affairs Medical Center, Durham, North Carolina.

Address correspondence to Sandro O. Pinheiro, Duke University School of Medicine, DUMC 3003-2511 Blue Zone, Durham, NC 27710. E-mail: sandro.pinheiro@duke.edu

DOI: $10.1111 /$ jgs.13824 demonstrated commitment to faculty development and improving learning experiences for medical learners. This faculty development program improved participants' selfefficacy in curriculum design and teaching and enhanced geriatrics education in their home institutions. J Am Geriatr Soc 63:2580-2587, 2015.

Key words: faculty development; curriculum development; geriatrics education

$\mathbf{P}$ roviding high-quality care for the growing population of older adults requires focused training in geriatrics for physicians, ${ }^{1-3}$ but the number of geriatricians in practice and medical learners choosing geriatrics as a subspecialty has declined. ${ }^{4}$ Stagnant resident enrollment in geriatrics fellowship programs and the projected increase in the number of older Americans means the shortage of geriatricians in the United States will continue to worsen. ${ }^{5}$ Faculty in practice, geriatrician and nongeriatrician, play an important role in filling this gap. As teachers, they are well positioned to educate their trainees about the unique aspects of caring for older adults, ${ }^{6,7}$ but to fill this role, these clinicians need targeted faculty development in geriatrics concepts and educational principles to become competent to train others to care for older adults.

Faculty development opportunities for geriatrics-oriented faculty are scarce. A review ${ }^{6}$ identified few geriatrics-oriented faculty development programs for internal medicine faculty, most of which focused on geriatrics subject knowledge and skills alone. Few of these addressed pedagogical or andragogical ${ }^{8}$ skills such as teaching and curriculum design. More-recent geriatrics-focused resident and faculty development programs have also continued the trend of emphasizing the teaching of geriatrics content. $^{9-11}$ 
In light of the growing need to advance geriatrics care, educators at Duke University offered a program to train geriatrician and nongeriatrician faculty to design, implement, and evaluate geriatrics education curricula. This article describes the program and the results of a mixedmethod evaluation ascertaining the program's effect on participants and their home institutions.

\section{PROGRAM DESCRIPTION}

\section{Background}

With funding from the Donald W. Reynolds Foundation, four leading medical schools (Duke, University of California at Los Angeles, Mount Sinai, and Johns Hopkins) formed the Consortium for Faculty Development to Advance Geriatrics Education (FD AGE) to design training programs to equip faculty as clinician educators. The development of the consortium and its activities have been described elsewhere. ${ }^{12}$ Although all shared the core purpose of strengthening faculty expertise in geriatrics education in U.S. academic health centers, each institution used slightly different methods in their approach to faculty development. The Duke program focused more specifically on skills in educational program development, teaching, and evaluation.

A group of clinician-educators in the Division of Geriatrics designed the Duke FD AGE program with the leadership of a professional educator (SP). The Duke University School of Medicine institutional review board reviewed the design, implementation, and evaluation strategies of the mini-fellowship and deemed them exempt. The faculty development literature informed the design, implementation, and evaluation of the program, ${ }^{13-16}$ which accounted for principles of adult learning and clinician-educators' needs. Specific evidence-based strategies included experiential learning, peer and expert mentoring, and use of multiple instructional methods. ${ }^{17}$

The Duke FD AGE program consisted of weeklong mini-fellowships focused on providing training and mentoring for clinician-educators in curriculum design and teaching. They were originally offered three times per year, each time with a different educational focus, including medical student education in geriatrics, long-term care, and palliative care. The same group of faculty offered these three programs annually from 2005 to 2009 with minimal modification in their implementation from year to year. Over its lifetime, the program has included mini-fellowships on other topics, including subspecialties in geriatrics, graduate medical education, and evidence-based medicine. This article focuses on the description and evaluation of the three original programs that formed the core of the Duke FD AGE program. Table 1 provides a sample schedule of one of the mini-fellowship programs. Four to six faculty members participated in the implementation of each program, co-teaching sessions and serving as mentors in each program, with an estimated preparation and delivery time of approximately 4 hours per faculty. Follow-up mentoring time varied depending on the involvement of the mentee. It is estimated that each faculty member spends an average of 3 to 5 hours of mentoring and follow-up activities per mini-fellowship program. Program coordinator support was also critical in the planning, implementation, and evaluation of the program. For recruitment, geriatrics, family medicine, and internal medicine organizations and program directors around the coun-

Table 1. Mini-Fellowship in Palliative Care Curriculum Development-Sample Schedule

\begin{tabular}{|c|c|c|c|c|c|}
\hline & Monday & Tuesday & Wednesday & Thursday & Friday \\
\hline PM & $\begin{array}{l}\text { Scholar arrival } \\
\text { 4:00-7:30 p.m. } \\
\text { Curriculum session: } \\
\text { Curriculum design } \\
\text { process }^{a} \\
\text { Dinner }\end{array}$ & $\begin{array}{l}\text { 1:00-5:00 p.m. } \\
\text { Curriculum observation: }{ }^{a} \\
\text { Palliative care seminar: } \\
\text { Communication skills and } \\
\text { how to teach them- } \\
\text { Part } 1\end{array}$ & $\begin{array}{l}\text { 1:00-3:00 p.m. } \\
\text { Curriculum observation: }^{\text {a }} \\
\text { Observation of palliative } \\
\text { care education fellows' } \\
\text { mini-retreat: "Culture" } \\
\text { 3:00-3:45 p.m. } \\
\text { Scholar debriefing of } \\
\text { curriculum observation } \\
\text { sessions }{ }^{\mathrm{a}} \\
\text { 4:00-5:00 p.m. } \\
\text { Educator's portfolio }\end{array}$ & $\begin{array}{l}\text { 1:00-2:00 p.m. } \\
\text { Palliative care seminars: }{ }^{\mathrm{a}} \\
\text { Engaging other professions } \\
\text { in the physician education } \\
\text { process } \\
\text { 2:00-3:00 p.m. } \\
\text { Teaching humanism } \\
\text { 3:00-4:00 p.m. } \\
\text { Ask the expert: palliative } \\
\text { medicine clinical services }\end{array}$ & Travel home \\
\hline Evening & Independent study time & Independent study time & Dinner with faculty & Independent study time & \\
\hline
\end{tabular}

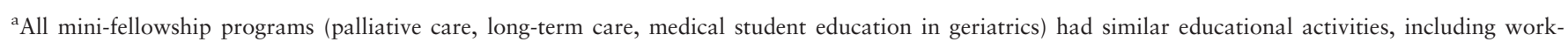

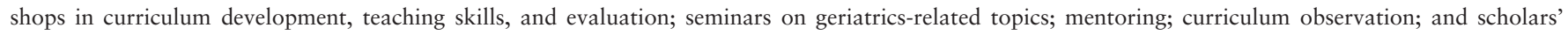
project presentation. 
try were contacted. Candidates submitted a brief application and letter of support from their institution, which Duke faculty reviewed and then selected five to eight to participate in each mini-fellowship.

\section{Program Activities}

\section{Advance Organizer and Assignments}

In preparation for the on-campus mini-fellowship week, scholars were assigned readings on adult learning theory and curriculum design in medical education. ${ }^{18,19}$ They submitted a preliminary educational plan for a project in their home institution (Appendix S1). These assignments served as advance organizers to facilitate the discussion on curriculum development and the process of teaching and learning. Their educational project plan served as an object for learning about designing and revising curricula. Scholars completed a preprogram self-efficacy survey regarding their confidence level in teaching and curriculum design.

\section{Workshop Sessions}

During the week on campus, scholars participated in several workshops that guided them through the process of designing, implementing, and evaluating a curriculum. The first workshop presented a framework for designing curricula. Scholars applied the framework to enhance their educational project plan as they learned to write measurable objectives, identify important content resources, and choose instructional strategies and evaluation methods for their educational project.

\section{Participant Observation}

In each of the mini-fellowships, scholars observed sessions that faculty taught at Duke to medical students, residents, or fellows. After observing these sessions, scholars were asked to evaluate and discuss them with the mini-fellowship Education Director (SP) in a focus group session that allowed scholars to take on the role of a curriculum evaluator and gave them the opportunity to discuss each of the major components of the teaching and learning process.

\section{Individual Mentoring}

Duke faculty members met with participants individually during the week to discuss and provide feedback on their educational project plan and career and professional development goals. This individualized mentoring relationship was designed to continue for at least 1 year after the scholars' visit to campus. Faculty and scholars maintained ongoing contact through e-mail, telephone, and occasional face-to-face sessions at national meetings. Mentors encouraged scholars to collaborate with faculty in conference presentations and publications.

\section{Independent Activities and Networking}

Throughout the week, scholars also had free periods during which they were able to network with faculty and peers, work on updating their educational project, and prepare for their end-of-the-week presentation. They reviewed existing printed and electronic geriatrics education resources and materials (e.g., The Portal of Geriatrics Online Education) that they could adapt to their projects.

\section{Scholars' Project Presentations}

The mini-fellowship week concluded with the scholars' presentation of their educational project plans to faculty and peers. Presentations focused on a brief overview of their projects, including rationale for their educational projects, description of goals and objectives, content, teaching and evaluation strategies, and perceived challenges to design and implementation. In response to the presentations, peers and faculty provided recommendations for improvement and suggestions to address challenges.

\section{Evaluation Methods}

As a primary outcome, the effect of the Duke mini-fellowship programs on participants' educational practices (curriculum design and teaching skills) and their subsequent effect on geriatrics education at their home institution were measured.

Quantitative and qualitative evaluation methods, ${ }^{20,21}$ including pre- and postprogram (end-of-week and end-ofyear) self-efficacy surveys, program evaluation forms (endof-week and end-of-year), and 6- and 12-month progress reports on the scholars' projects were used. The plan included formative and summative measures and sought to address Kirkpatrick's ${ }^{22}$ four levels of evaluation.

\section{Quantitative Data Sources}

Participants completed a 12 -item pre- and post-mini-fellowship self-efficacy survey (Appendix S2) on aspects of curriculum development and teaching. The 12 items listed specific educational tasks and asked participants to indicate their level of confidence in performing them on a 5 -point Likert scale $(1=$ not confident at all to $5=\mathrm{com}$ pletely confident). The self-efficacy presurvey was collected by e-mail before participants arrived at Duke for the week of training. The self-efficacy postsurveys were collected at two points: one immediately after the completion of the on-campus training week and a second 12 months later. Baseline assessments of self-efficacy (premini-fellowship) were compared with immediate postmini-fellowship and 1-year surveys using paired t-tests without adjustment for covariates. All analyses were performed using SAS version 9.3 (SAS Institute, Inc., Cary, $\mathrm{NC})$.

At the end of the training week, participants completed a program evaluation survey indicating their level of satisfaction with various aspects of the program, including assignments, workshops, mentoring, achievement of objectives, clarity of program expectations, and overall experience. They also provided recommendations for improvement of the program.

\section{Qualitative Data Sources}

Participants submitted a project follow-up report 6 and 12 months after the mini-fellowship training program. The formative 6-month follow-up report focused on the 
development and implementation of their project and identified resources needed to accomplish their project goals. The summative 12-month report focused on project implementation and asked them to reflect on successes and barriers encountered in the process.

Participants completed an end-of-year program feedback survey on various aspects of the mini-fellowship program and on knowledge and skills learned. Participants reflected on the most- and least-effective aspects of the program, how it affected their practice as clinician educators, and how it might have affected their institution and geriatrics education. As a means of assessing participants' scholarly productivity, they were asked to submit educational materials and to list publications and conference presentations.

The program education director (SP) and the mini-fellowship directors (MH, HW, KAE) read these follow-up reports and end-of-year program evaluations and analyzed them using constant comparative analysis with words and phrases as key units. The goal of the analysis was to identify themes in the reports regarding the effect of the program on participants' knowledge and skills in curriculum design and teaching and on geriatrics education in their home institution. An effort was also made to identify areas for improvement of the program. Reviewers met regularly to review and discuss findings and reconcile any differences.

\section{RESULTS}

\section{Quantitative Results}

Eighty-three scholars participated in the Duke mini-fellowship programs from 2005 to 2009 . Twenty-six (31\%) participated in long-term care, $28(34 \%)$ in palliative, and 29 $(35 \%)$ in medical student education in geriatrics. Of these, 47 specialized in internal medicine, 27 in family medicine, two in general surgery, one in psychiatry, one in rehabilitation medicine, and one in emergency medicine. Four nonphysician faculty involved in geriatrics education participated in the program: two nurse practitioners, one pharmacist, and one basic science faculty member. Three scholars participated in more than one mini-fellowship. Table 2 provides detailed demographic information.

Participants represented 52 different institutions from across the United States. Although the majority of participants were the only representative from their institution, 14 sent multiple attendees (range 2-5). Forty-six percent of participants were assistant professors. Several were associate professors and had program directorship responsibility. A few professors were chairs of departments.

Participants' purposes for joining the program varied, although most hoped that the program would provide them with tools to function better as teachers, curriculum developers, and evaluators. Their institutions encouraged and supported several participants to participate in the program because they were assigned curricular responsibilities, including leading a curriculum in geriatrics or palliative care and directing a clerkship or rotation, and these institutions hoped the program would help the faculty in accomplishing these tasks and responsibilities. Others chose to participate because they were seeking or securing

\begin{tabular}{|c|c|}
\hline Characteristic & n (\%) \\
\hline \multicolumn{2}{|l|}{ Sex } \\
\hline Male & $42(51)$ \\
\hline Female & $41(49)$ \\
\hline \multicolumn{2}{|l|}{ Specialty } \\
\hline Family medicine & $27(32)$ \\
\hline Internal medicine & $47(57)$ \\
\hline Other & $9(11)$ \\
\hline \multicolumn{2}{|l|}{ Status } \\
\hline Resident & $4(5)$ \\
\hline Fellow & 7 (8) \\
\hline Instructor & $1(1)$ \\
\hline Assistant professor & $38(46)$ \\
\hline Associate professor & $11(13)$ \\
\hline Professor & $5(6)$ \\
\hline Other & $13(16)$ \\
\hline Not specified & $4(5)$ \\
\hline \multicolumn{2}{|l|}{ Geriatrics training } \\
\hline Fellowship or certificate of added qualification in geriatrics & $49(59)$ \\
\hline No geriatrics training & $34(41)$ \\
\hline \multicolumn{2}{|l|}{ Institution affiliation } \\
\hline University-affiliated health center & $54(65)$ \\
\hline Community-based health center & $26(31)$ \\
\hline Other & $3(4)$ \\
\hline
\end{tabular}

employment as clinician educators and wanted to be equipped to serve in this role. Although their institutions provided most scholars with time and resources to participate in the program, a few used vacation time and personal resources to attend the program.

Seventy-nine scholars $(95 \%)$ completed the on-campus training self-efficacy pre- and postsurvey and program feedback form. Of these, $44(56 \%)$ completed the end-ofyear self-efficacy survey and end-of-program evaluation. Mean before and after self-efficacy results indicated statistically significant gains $(P<.001)$ across all 12 items assessed at 1 week and 1 year. The average item improvement in self-efficacy was 1.40 from before to immediately after training and 1.31 from before to 1 year after training. Scholars reported the largest average gains at the 1 -year mark in applying adult learning principles in the design of educational programs (1.72), writing measurable learning objectives (1.51), identifying instructional methods best suited to deliver learning objectives (1.50), and identifying strategies to assess learners (1.42). Figure 1 summarizes the comparison of self-efficacy results before and after training and 1 year after training.

End-of-week program evaluation survey results indicated a high level of satisfaction among scholars. Participants' overall mean rating for the mini-fellowships was 4.6 on a 5.0 scale. All scholars agreed or strongly agreed that the mini-fellowship activities were overall well organized and effective in accomplishing their purpose. The highest-rated activities were the workshop on designing educational programs (4.9) and the individual mentoring meeting with Duke faculty (4.8).

Scholars reported different types of educational achievements in their 6- and 12-month follow-up reports. Specific work included development of new courses, 


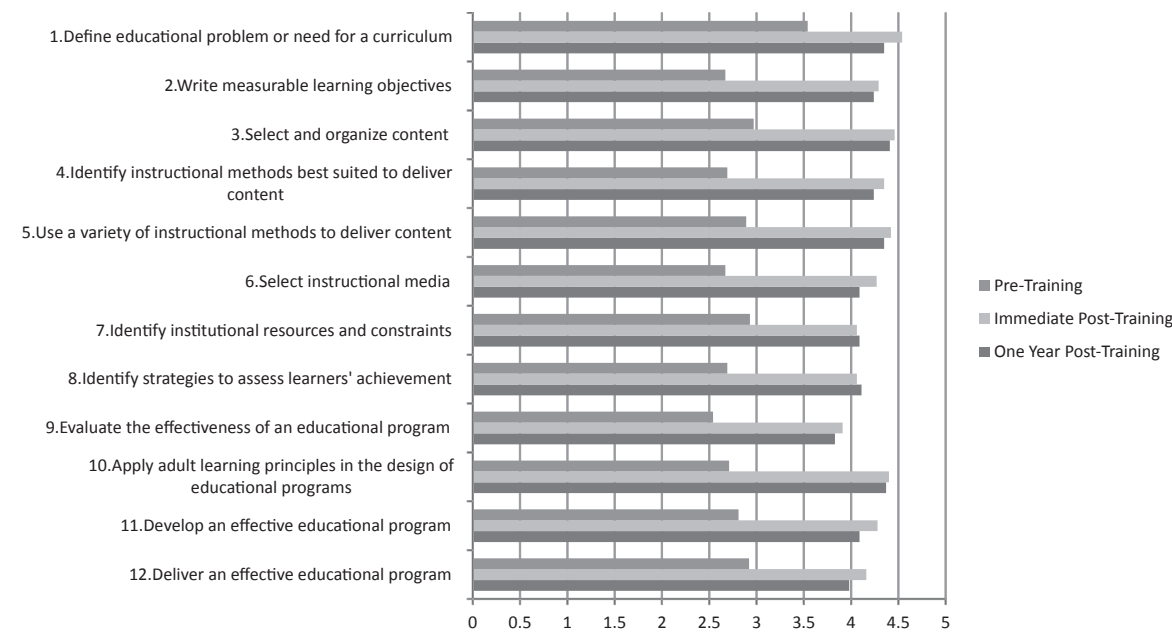

Figure 1. Comparison of scholars' pretraining and immediate posttaining and 1-year posttraining self-efficacy results $(\mathrm{N}=44$; $56 \%)$.

rotations, and online curricula; review and enhancement of existing curricula; implementation of active learning strategies in their teaching practices; implementation of new evaluation strategies; development of scholarly products related to their educational projects; and implementation of faculty development activities. Table 3 lists examples of activities that scholars developed to enhance geriatrics education in their home institution and beyond.

\section{Barriers to Implementing Educational Projects}

Scholars also listed in the 6- and 12-month follow-up reports the challenges they encountered while implementing their curricula. Barriers cited included lack of protected time for teaching and curriculum development; lack of academic recognition for curriculum design and teaching work; limited resources (e.g., faculty, administrative assistant); resistance by faculty or institution to implementation of innovative teaching and evaluation procedures; learners'

Table 3. Educational Activities That Scholars Developed

\section{Online learning}

Geriatrics oncology online module with pre- and posttests

One-hour interactive module on running a family meeting

Clinical learning experiences in geriatrics

Clinical geriatrics course for first-year medical students

Creation of a 3-half-day program on the essentials of clinical care of older adults for third-year medical students

Establishment of a geriatrics consultation clinic [to provide clinical experiences for learners]

Development of three Objective Structured Clinical Examination stations to assess geriatrics fellows' skills in delivering bad news, withdrawing and withholding treatment, and managing pain

\section{Workshops}

Communication skills workshop for residents

Implementation of the role-play method to teach family medicine residents about advance directives

Faculty development seminars on effective teaching strategies based on material from the Duke program lack of motivation for learning about geriatrics; and lack of faculty development opportunities for the scholars themselves and their colleagues.

\section{Qualitative Findings}

\section{Effect of Program on Scholars and Their Home Institution}

The end-of-year program evaluation report indicated that the program has had a meaningful effect on the scholars as clinician educators and in the educational process in their home institutions. Scholars reported increased confidence in their role as teachers and curriculum developers. One said, "Participation in the mini-fellowship exposed me to a whole new arena with which I had no prior experience. It helped me to think about how I teach and gave me a confidence to begin to reassess how and what I do." Another scholar stated, "I give considerably more thought to adult education principles when choosing teaching methods. I also try to vary teaching methods more than I used to." With regard to understanding and applying concepts learned about curriculum development one scholar wrote, "The framework of curriculum design described in the mini-fellowship program was helpful in planning and implementing curriculum revision. Using the framework helped me to think through the process from start to finish...." Another said, "I had little knowledge on how to evaluate a curriculum prior to this program. I learned useful techniques to design and test objectives."

Scholars seem also to have become more critical of their educational practice and proactive in implementing changes to enhance learning in geriatrics education. One scholar wrote, "I now appreciate the need to be methodical in assessing needs, designing curricula and content to meet that need, and how to evaluate the effectiveness of a program." Another said, "I spend more time and effort on the evaluation phase. As a result, I am constantly tweaking the curriculum as I go along rather than waiting to year end." Another also stated, "I give more attention to measurable outcomes and pre-intervention skills. I am better 
equipped with the language of adult education." Scholars also affected their institutions through their educational endeavors. They reported developing and implementing new geriatrics curricula, reviewing and enhancing existing curricula and educational activities, and implementing faculty development activities.

\section{Effective Aspects of the Program and Recommendations for Its Improvement}

Scholars were asked in the end-of-program evaluation report to list aspects of the program that were beneficial to them and areas in which it could be improved. The two most-effective aspects of the program were mentoring and learning about effective educational strategies. Scholars appreciated having the opportunity to meet with Duke faculty and discuss their project. One scholar stated, "The most effective aspect of the mini-fellowship was the mentoring I received from the [faculty] on my project over the past year. It was great to get a foundation of curriculum design fundamentals; the feedback on the specifics of my project was the icing on the cake. It was really nice to know there was someone that would look over my ideas and give me constructive feedback on my project. The mentoring gave me the confidence to propose a major curriculum revision [at my institution]." Scholars also indicated that participating in program activities was beneficial in exposing them to effective educational strategies. One scholar said, "Creating and implementing the [curriculum] project was extremely useful. Learning new evaluative methods has been helpful." Another stated that. "Observing a curriculum in action was very stimulating and revealing," and another said, "Being exposed to scholarly group of clinicians-something I was not used to-was exciting and helpful for me to learn how to start a curriculum."

Although scholars reported high satisfaction with the program, they provided critical feedback for its improvement in the end-of-year program evaluation report. Although mentoring was viewed as one of the most valuable aspects of the program, several scholars stated that they would have liked to have had more time for the oneon-one mentoring session with faculty. Another recommendation was to provide more time for scholars and faculty to discuss clinical topics in geriatrics.

\section{DISCUSSION}

The results of this mixed-method evaluation suggest that Duke FD AGE has affected scholars and their institution in a variety of ways. Scholars' self-efficacy in curriculum design and teaching improved immediately after the program and was sustained after 12 months. The largest average gains were in core educational skills, including identifying strategies to assess learners, identifying appropriate instructional methods to deliver learning objectives, writing measurable learning objectives, and applying adult learning principles in the design of educational programs. Although a decline was observed in the scores between the 1 -week training and the 1-year self-efficacy assessment in 10 of the 12 items, it was small and not statistically significant. It is conceivable that, 1 year after the 1 -week training, after scholars had the opportunity to further develop and try to implement their curriculum project, they were more realistic about their knowledge and skills and therefore scored themselves lower in the items assessed. Regardless, gains remained significant when compared with preprogram self-efficacy. The program's effect was also evident through scholars' descriptions of the unique concepts and skills they learned and are now applying in their home institution. Overall, scholars have improved knowledge and skills in designing geriatrics curricula, enhanced their confidence level as teachers and faculty, implemented new and revised geriatrics curricula, and demonstrated commitment to faculty development and improving learning experiences for medical learners. Faculty development programs for general medical faculty, which followed similar approaches as the Duke FD AGE program, have also reported success in affecting participants' teaching skills and curriculum development activities in their home institutions. ${ }^{15,23}$

The program's success may be attributed to its deliberate design to equip faculty with educational skills that would assist them in developing and implementing educational programs that promote active learning. The critical elements of the program consisted of pre-assignments including readings and development of a first draft of an educational project plan, which served as advance organizers to prepare the scholars for the on-campus training week; participation in highly interactive workshops in curriculum design and teaching skills, which provided scholars with tools to further develop their educational project and teaching methods repertoire; participation as participant-observers of a curriculum in action, where scholars had the opportunity to evaluate a curriculum and identify effective and ineffective aspects of an educational program; one-onone mentoring by Duke faculty, with whom scholars were able to discuss and receive individual feedback on their projects and other educational endeavors; and scholars' individual presentations of their projects to peers and faculty to receive feedback and establish possible opportunities for collaboration. The last element was particularly effective because nongeriatricians were able to interact and receive advice on their projects from their geriatrician colleagues, especially in the area of clinical content, indicating that the mix of geriatricians and nongeriatricians in the group created a unique opportunity for learning across disciplines.

It is important to acknowledge the limitations of this program. Although it was learned from the quantitative and qualitative measures that the program seemed to have had a substantial effect on participants' curriculum design and teaching practice, this outcome was self-reported, and it was not possible to verify the results objectively by observing participants' teaching practice or obtaining feedback directly from their learners. Implementation of these evaluation activities would have strengthened the conclusions about program effectiveness. Another major limitation was the modest response rate achieved at the end of the program. Although participants were e-mailed several times, responses were received from only $56 \%$ of the scholars, which limits conclusions about the effect of the program because the successes, challenges, and accomplishments of the nonrespondents are unknown. With respect to feasibility and dissemination, a program of this magnitude may be difficult to implement without adequate institutional resources. In Duke's case, a multiyear grant allowed devel- 
opment, implementation, and evaluation of the program, and a renewal for an additional 4-year period in 2011 supported its continued refinement and reach. Based on qualitative analysis, the most important and valuable elements for participants were learning about specific educational strategies and individual mentoring. In the absence of resources to re-create the program in its totality at individual institutions, training in specific strategies and principles can be delivered in workshops at national meetings or even virtually in webinars. Individual mentoring may present a moresignificant challenge, but mentoring programs conducted at the annual meeting of the American Geriatrics Society and in discrete workshops such as Teachers' Methods Swaps have allowed trainees and junior faculty to access the expertise and experience of more-senior educators. Finally, some of the scholars had hoped to have more time to discuss clinical topics in geriatrics. They assumed that the program would teach them about geriatrics. It was learned that it was necessary to be more explicit in the marketing materials about the focus of the program. These changes were made to accurately reflect the focus on education.

In conclusion, participant evaluations demonstrated the effectiveness of this program's interactive, collaborative, experiential design. These scholars are now uniquely equipped to continue to design and implement programs in geriatrics education that will meet the needs of teachers and learners at their institutions. The program has also provided them with a source of mentoring and community that will help them solve problems and develop in their careers as education leaders in geriatrics education. The program's success reflects, in many respects, the collective creativity and expertise of the entire FD AGE consortium. ${ }^{12}$ It is planned to publish results of shared participant survey items from all four programs in the future, although the Duke FD AGE program offers a unique development opportunity in its focus on curriculum design and implementation in geriatrics education. With the ongoing support of the Reynolds Foundation, faculty will continue to be enrolled in mini-fellowships through 2015. Beyond the term of this grant, it is hoped that it will be possible to continue to offer training and mentoring to physician educators for a modest tuition and to expand it to include other health professionals and international audiences.

\section{ACKNOWLEDGMENTS}

The authors would like to thank Ms. Emily Herbert and Ms. Michele Burgess, program coordinators, for their work in administering the program and assistance with the entry and management of the evaluation data, and $\mathrm{Mr}$. Richard Sloane, for his assistance with the quantitative data analysis.

This work was supported by a grant from the Donald W. Reynolds Foundation.

Conflict of Interest: The editor in chief has reviewed the conflict of interest checklist provided by the authors and has determined that the authors have no financial or any other kind of personal conflicts with this paper.

Author Contributions: Pinheiro, Heflin, White, Buhr, Elbert-Avila, Cohen: study concept and design. Pinheiro, Heflin, White, Buhr, Elbert-Avila: data acquisition. Pin- heiro, Heflin, White, Buhr, Elbert-Avila: data analysis and interpretation. Pinheiro: drafting of the manuscript. Pinheiro, Heflin, White, Buhr, Elbert-Avila, Cohen: critical revision of manuscript for important intellectual content. Pinheiro, Heflin, White, Buhr, Elbert-Avila, Cohen: approval of final version of manuscript.

Sponsor's Role: None.

\section{REFERENCES}

1. Institute of Medicine. Retooling for an Aging America: Building the Healthcare Workforce. Washington, DC: The National Academies Press, 2008.

2. Leipzig R, Granville L, Simpson D et al. Keeping granny safe on July 1: A consensus on minimum competencies for graduating medical student. Acad Med 2009;84:604-610.

3. Williams BC, Warshaw G, Fabiny AR et al. Medicine in the 21st century: Recommended essential geriatrics competencies for internal medicine and family medicine residents. J Grad Med Ed 2010;2:373-383.

4. Geriatric Workforce Policy Center [on-line]. Available at http://www.americangeriatrics.org/advocacy_public_policy/gwps/gwps_faqs/id:3185 Accessed April 24, 2015.

5. Boult C, Counsell S, Leipzig R et al. The urgency of preparing primary care physicians to care for older people with chronic illnesses. Health Aff 2010;29:5811-5818.

6. Rubin CD, Stieglitz H, Vicioso B et al. Development of geriatrics-oriented faculty in general internal medicine. Ann Intern Med 2003;139:615-622.

7. Levine SA, Caruso LB, Vanderschmidt $\mathrm{H}$ et al. Faculty development in geriatrics for clinician educators: A unique model for skills acquisition and academic achievement. J Am Geriatr Soc 2005;53:516-521.

8. Knowles MS. The Modern Practice of Adult Education: From Pedagogy to Andragogy. Englewood Cliffs, NJ: Cambridge Adult Education, 1980.

9. Podrazik PM, Levine S, Smith S et al. The curriculum for the hospitalized aging medical patient program: A collaborative faculty development program for hospitalists, general internists, and geriatricians. J Hosp Med 2008;3:384-393.

10. Levine SA, Chao SH, Brett B et al. Chief resident immersion training in the care of older adults: An innovative interspecialty education and leadership intervention. J Am Geriatr Soc 2008;56:1140-1145.

11. Mazotti L, Mylan A, Murphy E et al. Advancing geriatrics education: An efficient faculty development program for academic hospitalists increases geriatric teaching. J Hospital Med 2010;5:54-546.

12. Heflin MT, Bragg EJ, Fernandez H et al. The Donald W. Reynolds Consortium for Faculty Development to Advance Geriatrics Education (FD AGE): A model for dissemination of subspecialty educational expertise. Acad Med 2012;87:618-626.

13. Wilkerson L, Armstrong E, Lesky L. Faculty development for ambulatory teaching. J Gen Intern Med 1990;5:S44-S53.

14. Hitchcock MA, Stritter FT, Bland CJ. Faculty development in the health professions: Conclusions and recommendations. Med Teach 1993;14:295309.

15. Pinheiro SO, Liechty DK, Busch KV et al. Institutional impact of a parttime faculty development fellowship program for osteopathic communitybased physicians. J Am Osteopath 2002;102:637-642.

16. Morzinski J, Simpson D. Outcomes of a comprehensive faculty development program for local-full time faculty. Fam Med 2003;35:434-439.

17. Steinert Y, Mann K, Centeno A et al. A systematic review of faculty development initiatives designed to improve teaching effectiveness in medical education: BEME Guide No. 8. Med Teach 2006;28:497-526.

18. Kern ED, Thomas P, Howard D et al. Curriculum Development for Medical Education: A Six Step Approach. Baltimore, MD: The Johns Hopkins University Press, 1998.

19. Svinicki MD. Practical implications of cognitive theories. New Direct Teach Learn 1991;45:27-37.

20. Creswell J, Plano Clark V. Designing and Conducting Mixed Methods Research. London: Sage Publications, 2007.

21. Shulman L. A Union of insufficiencies: Strategies for teacher assessment in a period of educational reform. Educ Leadership 1988:36-46.

22. Kirkpatrick DL. Evaluating Training Programs, 2nd Ed. San Francisco: Berret-Koehler Publishers, 1998.

23. Armstrong EG, Doyle J, Bennet N. Transformative professional development of physicians as educators: Assessment of a model. Acad Med 2003;78:702-708. 


\section{SUPPORTING INFORMATION}

Additional Supporting Information may be found in the online version of this article:

Appendix S1 Educational Project Plan - Mini-Fellowship in Palliative Care Curriculum Development
Appendix S2 Self-Assessment of Curriculum Design and Teaching Duke Mini-Fellowship Programs

Please note: Wiley-Blackwell is not responsible for the content, accuracy, errors, or functionality of any supporting materials supplied by the authors. Any queries (other than missing material) should be directed to the corresponding author for the article. 